CIRJE-F-569

\title{
A Reappraisal of the Incidence of Employer Contributions to Social Security in Japan
}

\author{
Junya Hamaaki \\ Graduate School of Economics, University of Tokyo \\ Yasushi Iwamoto \\ University of Tokyo
}

June 2008

CIRJE Discussion Papers can be downloaded without charge from:

http://www.e.u-tokyo.ac.jp/cirje/research/03research02dp.html

Discussion Papers are a series of manuscripts in their draft form. They are not intended for circulation or distribution except as indicated by the author. For that reason Discussion Papers may not be reproduced or distributed without the written consent of the author. 


\title{
A reappraisal of the incidence of employer contributions to social security in Japan*
}

\author{
Junya Hamaaki ${ }^{\dagger}$ and Yasushi Iwamoto ${ }^{\ddagger}$ \\ University of Tokyo
}

June 2008

\begin{abstract}
This paper reappraises Tachibanaki and Yokoyama (2008) - an empirical analysis that indicates no apparent backward shifting of employer social insurance contributions - by modifying their empirical strategy. First, we attempt to control for a spurious positive correlation between wages and employer's contribution rates by trend variables. Second, we exclude two industries from our sample that have small numbers of workers and establishments to remove sampling errors in wages. Our results imply that the social insurance burden shifts back on to employees to a certain extent, contrary to Tachibanaki and Yokoyama (2008). Our finding is consistent with other existing studies.
\end{abstract}

JEL Classification: H55, H22, J38

Key words: Social insurance, Payroll-tax incidence, Employer contribution

\section{Introduction}

The effects of increasing social insurance contributions on business activity and living standard of people have concerned many researchers. In particular, the way employer's contribution to social insurance programs affects wages has recently attracted much research, but remains controversial among empirical studies of Japan. By conducting a pooled regression analysis on industrial-level data, Tachibanaki and Yokoyama (2008) concluded that "there is no apparent backward shifting on to employees, and thus that

*This paper is drawn from the paper presented at JEA Spring Meeting in 2007. We are grateful to Kohei Komamura, Yukiko Abe, and Shunichiro Bessho for their useful comments. This research is financially supported by the 21st Century Center of Excellence (COE) program in the Graduate School of Economics, the University of Tokyo and by the Grant-in-aid for Scientific Research 20330062 from the Ministry of Education. Remaining errors are solely on our own responsibility.

†E-mail: ee57016@mail.ecc.u-tokyo.ac.jp

${ }^{\ddagger}$ E-mail: iwamoto@e.u-tokyo.ac.jp 
employers bear nearly all part of their portion of social security contributions in Japan" (p.81).

By contrast, Komamura and Yamada (2004), Sakai and Kazekami (2007) and Iwamoto and Hamaaki (2006) found a partial or full shifting onto employees. Komamura and Yamada (2004) analyzed the incidence of the employers' contribution rates to health insurance and long-term care insurance. They used panel data of individual health insurance society throughout Japan during the period from 1995 to 2001. They found that a "majority of the employer's contribution rate to health insurance was shifting back onto the employees in the form of wage reduction" (p.579). Also, Sakai and Kazekami (2007) investigated the payroll tax incidence by utilizing the introduction of long-term care insurance in 2000 as a natural experiment and found "the decrease in the wage after 2000 merely for male employees aged over forty, which indicates that male workers partially bear the employer's burden" (p.301). Moreover, Iwamoto and Hamaaki (2006) focused on endogeneity problems in the estimation strategies of Komamura and Yamada (2004) and Tachibanaki and Yokoyama (2008). Our additional empirical findings are internally inconsistent unless a coefficient is biased. We pointed out that a partial incidence hypothesis can explain the findings with the least number of endogeneity biases.

This paper reappraises Tachibanaki and Yokoyama's (2008) findings by carefully looking at a way of identifying variations of wages and contribution rates. We attempt to improve the empirical strategy through the following ways. First, as pointed out in our previous paper (Iwamoto and Hamaaki [2006]), both the wage and the contribution rate have a positive time trend. Their spurious positive correlation would bias the coefficient of the employer's contribution rate upwardly. Time trend variables are included in estimated equations to deal with the spurious regression problem, but the burdens on the employers are not observed. Secondly, in the present paper, we focus also on the fact that the wages in the mining and the real estate industries exhibited an unusual short-run fluctuation. This might be the result of sampling error due to the small numbers of the workers and the establishments in those industries. We remove those industries from our sample, because there is no appropriate way of remedying those data. After adding these two refinements, our estimated effect of the employer's contribution on the market wage is in fact negative, suggesting that Tachibanaki and Yokoyama's (2008) results might be biased due to the above factors. Our finding is corroborated by previous studies of other countries, for example Chile (Gruber [1997]), Columbia (Kugler and Kugler [2003]), Sweden (Holmlund [1983]), the U.K. (Hamermesh [1979]) and the U.S. (Gruber and Krueger [1991], Gruber [1994, 1997], Anderson and Meyer [2000]).

This paper is organized as follows. Section 2 discusses the identification issues on the variations of wages and contribution rates. Section 3 shows the estimation results obtained by modifying the specification of Tachibanaki and Yokoyama (2008). Section 4 presents a conclusion of this paper. 


\section{Issues in identifying variations of variables}

\subsection{Trends in the contribution rates}

Tachibanaki and Yokoyama (2008) examined the incidence of employers' contributions by estimating the following equation:

$$
\log w=\alpha+t_{f} \beta+x \gamma+\epsilon
$$

where $w$ is a real hourly-wage rate; $t_{f}$ is the employer's contribution rate in percentage figure; and $x$ is a vector of other explanatory variables. The real hourly-wage rate is obtained by dividing the nominal hourly-wage rate (monthly total wage/monthly total working hours) by the consumer price index for Japan (general excluding fresh food). The monthly total wage and working hours are derived from Monthly Labor Survey (National Survey), conducted by the Ministry of Health, Labor and Welfare (formerly Ministry of Labor). ${ }^{1}$ The employer's contribution rate is taken from the Yearbook of Social Security. Tachibanaki and Yokoyama (2008) used industrial-level data during the period from 1971 to 1998, which contained the following nine major industries: (1) mining, (2) construction, (3) manufacturing, (4) electricity and gas, (5) transport and communications, (6) wholesale and retail trade, (7) finance and insurance, (8) real estate and (9) services. The employer's contribution rate included the portion in health insurance, employees pension, and unemployment insurance. After estimating eq. (1) by weighted least squares, they concluded that the employer's contribution rate did not shift back onto employees. In some cases, contrary to theoretical expectations, the social security burdens on employers caused an increase in the wage.

First, let us consider the factors responsible for variations in the employer's contribution rate in Tachibanaki and Yokoyama (2008). Since they used annual data of nine industries in estimating eq. (1), variations in the employer's contribution rate came from the following two kinds of variations: (1) cross-industry variation, and (2) time-series variation. The cross-industry variation stemmed only from the difference in the contribution rate of unemployment insurance between the construction industry and others, which is merely about 0.2 percentage points difference. On the other hand, the time-series variation was derived from revisions conducted by the national government and individual health insurance societies on the contribution rate in each insurance system-for example, the contribution rates of health insurance and employees pension had been raised gradually as the population ages or the pension system develops, and that of unemployment insurance had been increased or decreased with economic trends. In Tachibanaki and

\footnotetext{
${ }^{1}$ In Tachibanaki and Yokoyama (2008), the component of the real hourly-wage rate came from Annual Report on the Monthly Labor Survey, which provides only the numbers of 'annual average' for the monthly total wage and the monthly total working hours. On the other hand, the numbers of employees were collected on December 31 each year. In order to match the timing of data, this paper uses the values of all these variables on December 31 each year given by Monthly Labor Survey (National Survey). The Annual Report on the Monthly Labor Survey is compiled from the observations of Monthly Labor Survey.
} 
Yokoyama (2008), therefore, most of the variations in the contribution rate depended on time-series variations.

Figures 1-1 to 1-4 show the time-series trends of the employer's contribution rate and the real hourly-wage rate of the manufacturing industry. Figure 1-1 suggests that the contribution rate and the wage positively correlated with each other. Hence, the coefficients of the employer's contribution rate are suspected to be positively biased in Tachibanaki and Yokoyama (2008). Further, Figure 1-3 reveals that the contribution rate of employees pension clearly has a positive correlation with the wage variable. On the contrary, Figures 1-2 and 1-4 present a weaker increasing trend and a lower level of contribution than Figure 1-3. This evidence indicates that the strong increasing trend of the contribution rate in Figure 1-1 is driven mainly by the trend of the contribution rate of employees pension. In order to control for this time trend, we add trend variables to eq. (1) in the following analysis.

\subsection{Variations of the wage}

We then look at variations of the wage variable. Figures 2-1 and 2-2 show that the wages of the mining and the real estate industries not only have a positive time trend but also an irrelevant short-run fluctuation, which would potentially bias the coefficients of independent variables. The small numbers of employees and establishments in these two industries are responsible for these fluctuations because sampling errors might be larger for the industry that has less employees and establishments. ${ }^{2}$ Table 1 provides the numbers of male regular employees working at establishments with 30 or more employees, which are given by Monthly Labor Survey (National Survey). ${ }^{3}$ This indicates that the mining and the real estate industries have had, respectively, the smallest and the second-smallest number of employees for all periods under study. Further, according to Establishment and Enterprise Census of Japan conducted by the Statistics Bureau, Management and Coordination Agency (formerly Prime Minister's Office), the mining and the real estate industries have had, respectively, the smallest and the third-smallest number of establish-

\footnotetext{
${ }^{2}$ We are greatly indebted to Yukiko Abe for this point.

${ }^{3}$ In Table 1 the number of employees belonging to the construction industry decreases dramatically in 1976. This is probably attributable to the re-sampling of establishments conducted in 1975. The resampled group of establishments were used for the statistical tabulation of Monthly Labor Survey since April 1976. The survey for April 1976 reports both numbers of employees in the construction industry that were computed based on the before re-sampled establishments (1662) and on the after re-sampled establishments (1044). It seems that the re-sampling entailed the sharp decrease in employees. However, we do not know the reasons for the decrease being observed only in the construction industry in 1976 even though a re-sampling has been conducted for all industries every 3 or 5 years. This paper uses the numbers of employees without an adjustment for the decrease in 1976 because we do not have any appropriate way to solve this phenomenon.
} 
ments with 30 or more employees, as presented in Table 2. ${ }^{4}{ }^{5}$ Although the sample design of Monthly Labor Survey is carried out so that the sampling error rate for contractual cash earnings falls in a fixed magnitude, the sampling error could be larger for the mining and the real estate industries due to a small number of their population. ${ }^{6}$ This sampling error potentially results in a short-term fluctuation of the wage. This paper therefore drops the observations of these two industries in order to estimate the coefficient precisely.

\section{Results}

\subsection{Outcome of two modifications}

In this section, we try to control for the spurious positive correlation between the wage and contribution rate and the short-run fluctuation of the wage, and then reveal a negative response of the wage to the employer's contribution rate.

Table 3 reports the estimation results of four different specifications of eq. (1). The vector of the explanatory variables $(x)$ in eq. (1) includes real industrial GDP, one-year lagged value of real hourly-wage rate, and one-year lagged value of labor input (product of monthly total working hours and number of male regular employees). The industrial GDP is taken from Annual Report on National Accounts, published by the Department of National Accounts, Economic and Social Research Institute, Cabinet Office (formerly Economic Planning Agency). The labor input is given by Monthly Labor Survey (National Survey). We use the data from 1971 to $2003 .{ }^{7}$ The equation is estimated by weighted least

\footnotetext{
${ }^{4}$ Monthly Labor Survey (National Survey) describes the sampling methodology as "Sample establishments are selected from a list of all establishments of the Establishment and Enterprise Census by a stratified one stage sampling method." Also, Establishment and Enterprise Census of Japan defines 'establishment' as "a single physical location where the economic activity is conducted and, as a general rule, following prerequisites are satisfied: (1) The economic activity is carried out, under a single entity of management, at a certain fixed place, occupying a demarcated area. (2) The production or supply of goods or services is done on a continuing basis with the help of people and equipment. In other words, the establishment is what is usually called a store, a factory, an office, a bank, a school, a hospital, a temple, a hotel, or the like."

${ }^{5}$ For the real estate industry, the ratio of the establishments with 30 or more employees to the total number of establishments is only $0.8 \%$ at most, which is exceptionally low compared with other industries. Hence, the time-series variation in the real hourly-wage rate in Figure 2-2 probably deviates from that of the average establishment. Figure 2-2 may show the time-series variation of extremely large-size establishments belonging to the top 1 percent of the real estate industry. The electricity and gas industry also has had a small number of establishments; however, the percentage of the establishments with 30 or more employees has been large, unlike the real estate industry. Therefore, the real hourly-wage rate of the electricity and gas industry appears to represent the value of the average establishment, and thus it has not behaved unsteadily.

${ }^{6}$ As for the major nine industries covered in this paper, Monthly Labor Survey is designed to keep the sampling error rates less than $2 \%, 2 \%$, and $0 \%$ for the establishments with 30-99 employees, 100-499 employees, and 500 or more employees, respectively. The sampling error rate is defined so that the true value from complete enumeration falls in a certain range of between plus and minus a sampling error rate centering on the estimated value, with probability more than $2 / 3$.

${ }^{7}$ The sample period of Tachibanaki and Yokoyama (2008) ended in 1998 because they used the data
} 
squares that use the number of employees in each industry as a weight, as Tachibanaki and Yokoyama (2008) did. Column (A) of Table 3 reproduces the estimation results of Tachibanaki and Yokoyama (2008), employing the same specification. The coefficient of the employer's contribution rate is significantly positive.

The first modification to column (A) is to deal with a positive time trend. As mentioned in Section 2-1, both the employer's contribution rate and the wage have a positive time trend, and thus the positive coefficient in column (A) probably reflects this trend. Following Iwamoto and Hamaaki (2006), we add a trend variable and its square to the specification of column (A). Column (B) reports the result of this specification and shows that the coefficient of the contribution rate is still positive, but somewhat smaller than column (A). ${ }^{8}$ This result is qualitatively the same as Iwamoto and Hamaaki (2006). A spurious positive correlation between these two variables is one of the possible reasons for the upward bias.

As already described in Section 2.2, the second modification is to remove a short-run fluctuation of the wage by excluding the observations of the mining and the real estate industries. The estimation results of this modification are shown in column (C), which tells that the coefficient of the contribution rate is much smaller than in columns (A) and (B). Therefore, this sample exclusion contributes substantially to a reduction in the upward bias of the coefficient of the contribution rate. But, it is still significantly positive. Adjusted $R^{2}$ goes up from approximately 0.94 in columns (A) and (B) to 0.99 by dropping two industries. This suggests that the goodness of fit is also greatly improved due to a reduction in the sampling errors of the wage. ${ }^{9}$

Finally, we estimate the wage equation with the trend variables using the data of the seven industries except the mining and the real estate industries. Column (D), which combines the above two modifications, reports a significantly negative coefficient of the employer's contribution rate. This indicates that controlling both for the short- and longrun variations of the wage yields a reasonably negative coefficient. The value of -0.018 implies that a 1 percentage point increase in the contribution rate decreases the market wage by 1.8 percentage in the short-run. Since the coefficient of the one-year lagged value of dependent variable is 0.731 , the long-run response of market wage to a 1 percentage point increase in the contribution rate is a drop of 6.8 percent $(-0.018 /(1-0.731))$. This

of 68 SNA, which includes only the data up to 1998, to obtain the data of industrial GDP. We extend the sample period to 2003 by connecting 93 SNA and 68 SNA in order to use more observations.

This paper, however, excludes the observations in 2003 from the sample period when estimations are conducted for health insurance and employees pension, because these two insurance programs started to collect the premiums from bonuses as well as monthly earning at a uniform rate in 2003. As this paper uses 'monthly contractual cash earnings' as a dependent variable $(w)$, which does not include the amount of bonuses, the observations in 2003 should be excluded from the sample period. Since unemployment insurance collects the premium from monthly earning throughout the sample period, the observations in 2003 are included in the sample period in the estimation for unemployment insurance.

${ }^{8}$ The estimates are slightly different from these of Iwamoto and Hamaaki (2006) because some inputting errors included are corrected.

${ }^{9}$ Only when we exclude both of the mining and the real estate industries, adjusted $R^{2}$ increases dramatically. The exclusion of other industries does not contribute to the improvement in goodness of fit. 
figure significantly deviates from the maximum incidence level of a 1 percent drop, which is predicted by theory, at the $5 \%$ significance level. ${ }^{10}$ In this column, the coefficients of the trend variables are also statistically significant, implying that these variables control for the time trend successfully. ${ }^{11}$

\subsection{Additional empirical results}

This section shows additional estimates of the coefficients of the employer's contribution rate. Several coefficients are estimated to be more reasonable in magnitude than ones in Table 3.

First, we estimate the same specification as column (D) of Table 3 according to insurance programs because a change in the contribution rate differs among these schemes. All three columns in Table 4 report negative coefficients of the employer's contribution rate. Among them, the coefficients for health and unemployment insurances are statistically significant. Since the contribution rates of these two insurances have a relatively-weak time trend, the upward bias to the coefficients might also be weak. On the other hand, the coefficient for employees pension is not statistically significant. This may be attributed to the fact that the contribution rate of this insurance has a strong increasing trend. Also, the coefficient for employees pension is reasonable in magnitude compared to theoretical prediction, but the other two coefficients in columns (A) and (C) are too small.

Next, we try to obtain a more reasonable coefficient by applying an alternative way of identifying the variations of the contribution rate. In order to alleviate the problem of the positive time trend in the wage, we now estimate eq. (1) with the use of two-year differenced data between one-year-before and one-year-after the change in the employer's contribution rate. We first estimate the differenced equation using the data of all periods. ${ }^{12}$ The estimation results, presented in column (A) of Table 5, indicate that the coefficient of the employer's total contribution rate is still positive (but insignificant). This is probably because the alternative strategy used here is only a partial solution to the positive correlation between the contribution rate and wages.

We then focus on the two-year differenced data before and after the large change in the contribution rate of employees pension. We try to estimate the incidence of the contribution rate more precisely by utilizing its large variations. Specifically, the employer's contribution rate of employees pension increased in 1973, 1976, 1980, 1985, 1990, 1991, 1994, and 1996. These increases come from public pension reforms conducted every about 5 years. Columns (B) and (C) of Table 5 report the results of this estimation. The coefficient of the employer's total contribution rate is estimated to be -0.010 , which

\footnotetext{
${ }^{10} F$ and $p$-values of the null hypothesis that the long-run response of market wage equals a 1 percent drop are 4.58 and 0.0334 , respectively.

${ }^{11}$ In Table 3, the signs of the coefficients of industrial GDP and one-year lagged value of labor input change from negative to positive and from positive to negative, respectively, if we exclude the observations of two industries in columns (C) and (D). The coefficients in these two columns have the same signs as ones of Tachibanaki and Yokoyama (2008).

${ }^{12}$ The observations of seven industries, except for the mining and the real estate industries, are used for estimations in this section.
} 
is considerably smaller in absolute value than in column (D) of Table 3. Moreover, we obtain much smaller coefficient value of -0.006 when we use the employer's contribution rate of employees pension as an independent variable. The long-run responses of market wage to a 1 percentage point increase in the contribution rate are a drop of 2.02 percent and 1.21 percent for columns (B) and (C), respectively. These two estimates of long-run response do not significantly deviate from the maximum incidence level, in contrast to the estimate in column (D) of Table 3. However, they are not statistically significant. Judging from these results, the upward bias to the coefficient is likely to be reduced to some degree by the alternative strategy, but standard errors may be estimated to be larger than it should be due to a lack of observations. ${ }^{13}$

\section{Conclusion}

Whereas Tachibanaki and Yokoyama (2008) found "no apparent backward shifting" of the employer's social insurance contribution rate, other studies have obtained opposite results. This paper reexamined Tachibanaki and Yokoyama's (2008) findings by modifying their empirical strategy. First, we controlled for a spurious positive correlation between the contribution rate and wages by trend variables in order to prevent the coefficient of the contribution rate being upwardly biased. Second, we excluded the observations of the mining and the real estate industries from estimations in order to remove unusual shortrun fluctuations of wages due to serious sampling errors in those industries. As a result of the control for the peculiar short- and long-run variations of wages, the coefficients of the contribution rate were estimated to be negative, which implies that Tachibanaki and Yokoyama (2008)'s coefficients are upwardly biased.

A limitation of our study is that we do not have rich variations of focused variables because of the use of aggregated data. Our baseline estimate of the response to market wage is larger than the theoretical limit. When we use only the observations on the occurrence of a large increase in social contribution, the magnitude of response is reasonable, but not statistically significant. Since this paper used an aggregated data of each industry, the estimates of the incidence of the contribution rate may not necessarily be precise. Using the micro-data of each worker would yield more accurate estimates because we can observe variations in the wage more correctly than the aggregated data. Furthermore, if we find a good natural experiment, the incidence may be estimated more precisely. However, Japanese social insurance reform cases that can be utilized for a natural experiment approach, wherein two groups are homogeneous except for the experience of reform, are difficult to find. Sakai and Kazekami (2007) is the only study that uses a natural experiment approach (specifically, difference-in-difference estimation), but unfortunately their treatment and control groups are divided by age (the age of persons in the treatment group is 40 and over; that in the control group is under 40). Further research using better

\footnotetext{
${ }^{13}$ We employ weighted least squares that use the number of employees as a weight in estimating the differenced equations. If we apply robust OLS that uses the heteroskedasticity-robust standard errors, results are rarely different from ones obtained by weighted least squares.
} 
data would obtain a more precise result.

\section{References}

[1] Anderson, Patricia, M and Bruce D. Meyer. 2000 "The Effects of the Unemployment Insurance Payroll Tax on Wages, Employment, Claims and Denials" Journal of Public Economics Vol.78. Nos.1-2.

[2] Gruber, Jonathan. 1994 "The Incidence of Mandated Maternity Benefits" American Economic Review Vol.84 No.3.

[3] Gruber, Jonathan. 1997 "The Incidence of Payroll Taxation: Evidence from Chile" Journal of Labor Economics Vol.15 No.3.

[4] Gruber, Jonathan, and Alan B. Krueger. 1991 "The Incidence of Mandated EmployerProvided Insurance: Lessons from Worker's Compensation Insurance" in David Bradford ed., Tax Policy and the Economy Vol.5, MIT Press.

[5] Iwamoto, Yasushi, and Junya Hamaaki. 2006 "On the Incidence of Social Insurance Contributions in Japan: An Economic Perspective" (Shakai Hokenryo no kichaku bunseki) The Quarterly of Social Security Research (Kikan shakai-hosho kenkyu) Vol.42. No.3. (in Japanese)

[6] Komamura, Kohei, and Atsuhiro Yamada. 2004 "Who Bears the Burden of Social Insurance? Evidence from Japanese Health and Long-term Care Insurance Data" Journal of the Japanese and International Economies Vol.18. No.4.

[7] Kugler, Adriana, and Maurice Kugler. 2003 "The Labor Market Effects of Payroll Taxes in a Middle-Income Country: Evidence from Colombia" Discussion Papers in Economics and Econometrics No.0306.

[8] Sakai, Tadashi, and Sachiko Kazekami. 2007 "Empirical Study on Incidence of Longterm Care Insurance" (Kaigo-hoken seido no kichaku bunseki) Journal of Health Care and Society (Iryo to shakai) Vol.16. No.3. (in Japanese)

[9] Tachibanaki, Toshiaki, and Yukiko Yokoyama. 2008 "The Estimation of the Incidence of Employer Contributions to Social Security in Japan" Japanese Economic Review Vol.59. No.1. 
Figure 1-1 Real hourly-wage rate and employer's contribution rate (Total)
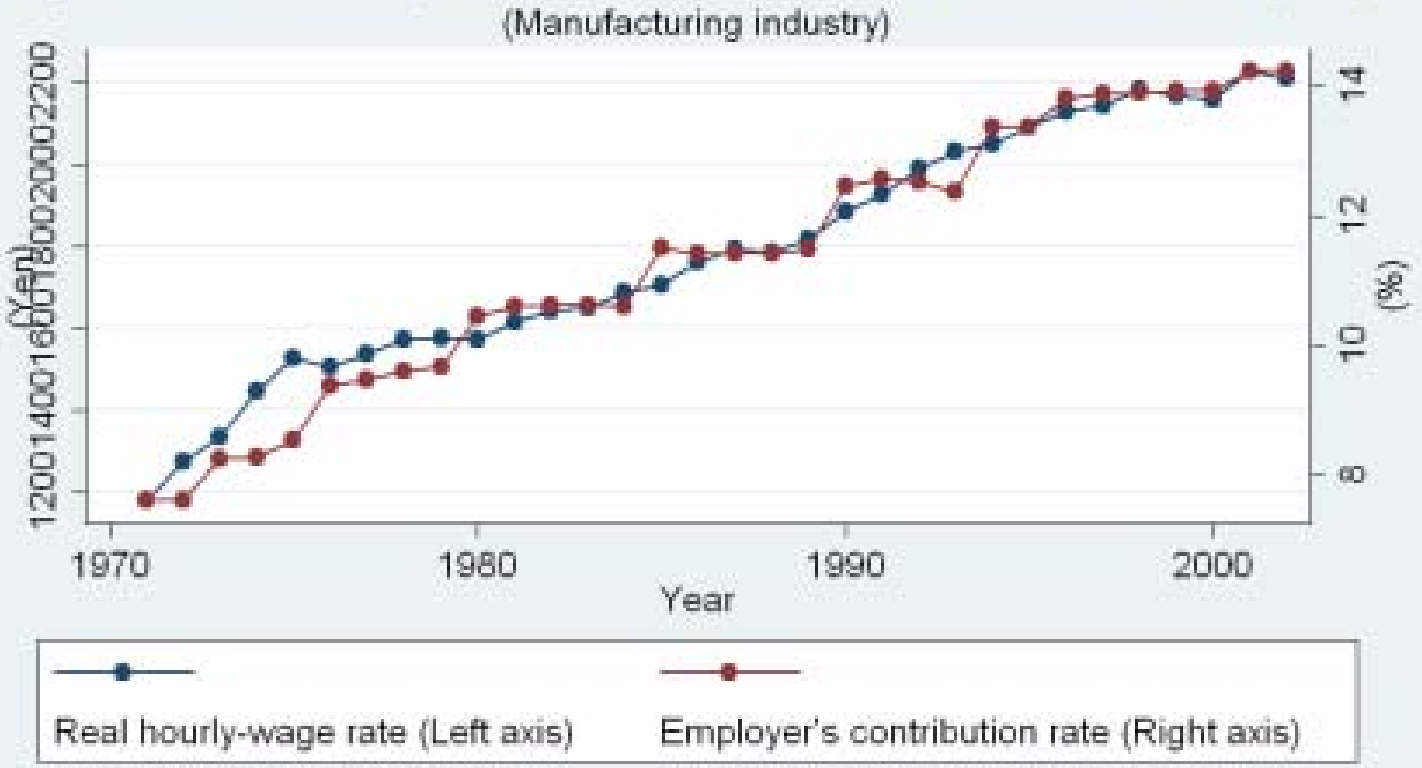

Note: Real hourty-wage rate is monthby total wageimonthly total working hours, which is deflated by Consumer Price Index for nationwide.

Source: Monthy Labor Survey. Annual Report on the Consumer Price Index, and Year book of Social Security (various issues).

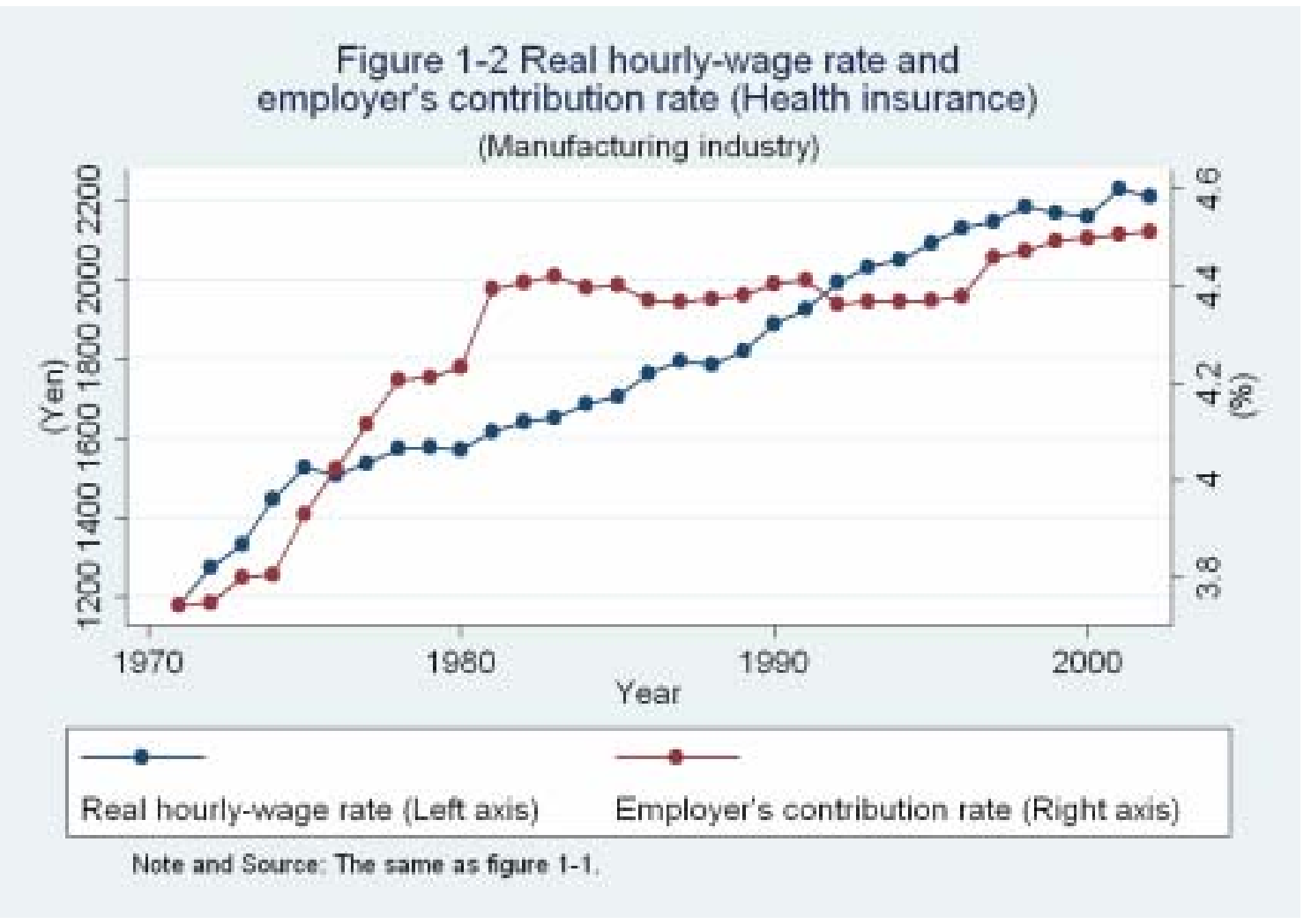


Figure 1-3 Real hourly-wage rate and employer's contribution rate (Employees pension) (Manufacturing industry)

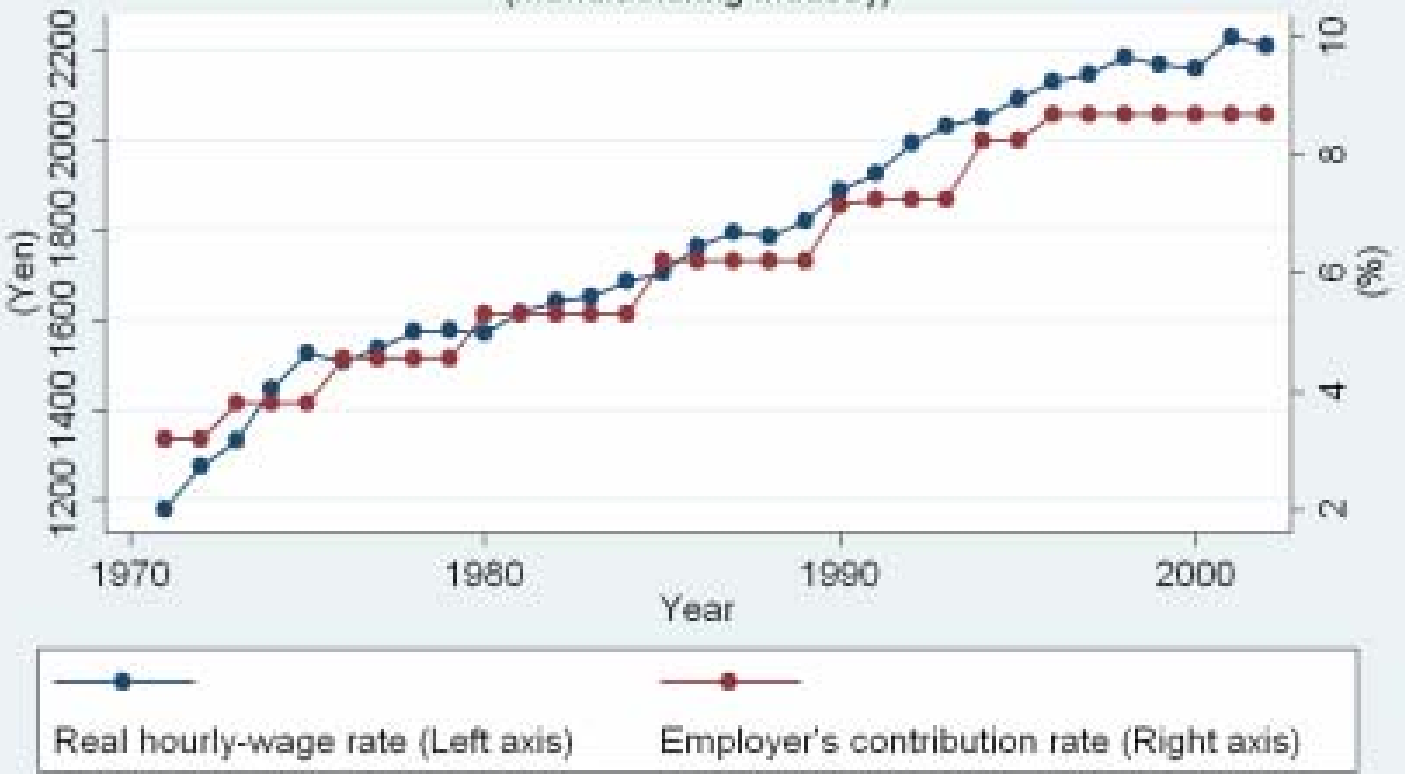

Note and Source: The same as figure 1-1.

Figure 1-4 Real hourly-wage rate and employer's contribution rate (Unemployment insurance) (Manufacturing industry)

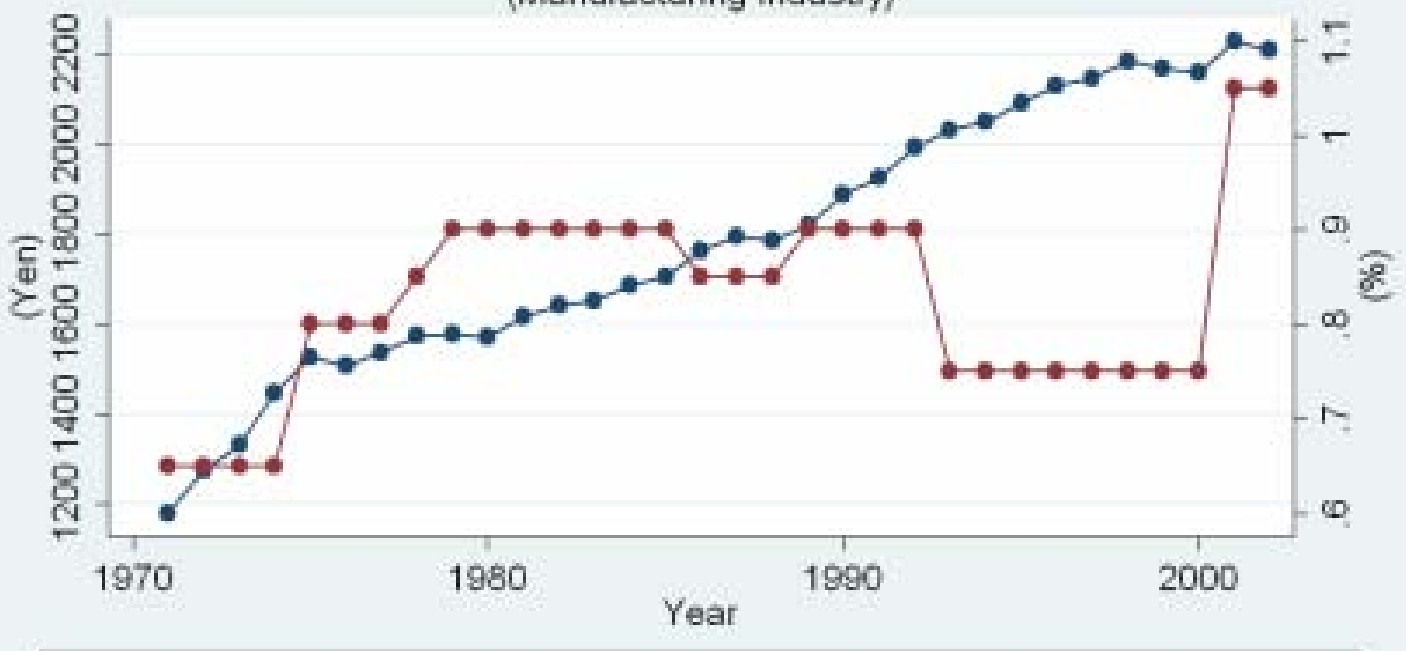

$\longrightarrow$ Real hourly-wage rate (Left axis) Employer's contribution rate (Right axis)

Note and Source: The same as figure 1-1. 
Figure 2-1 Real hourly-wage rate (Mining industry)

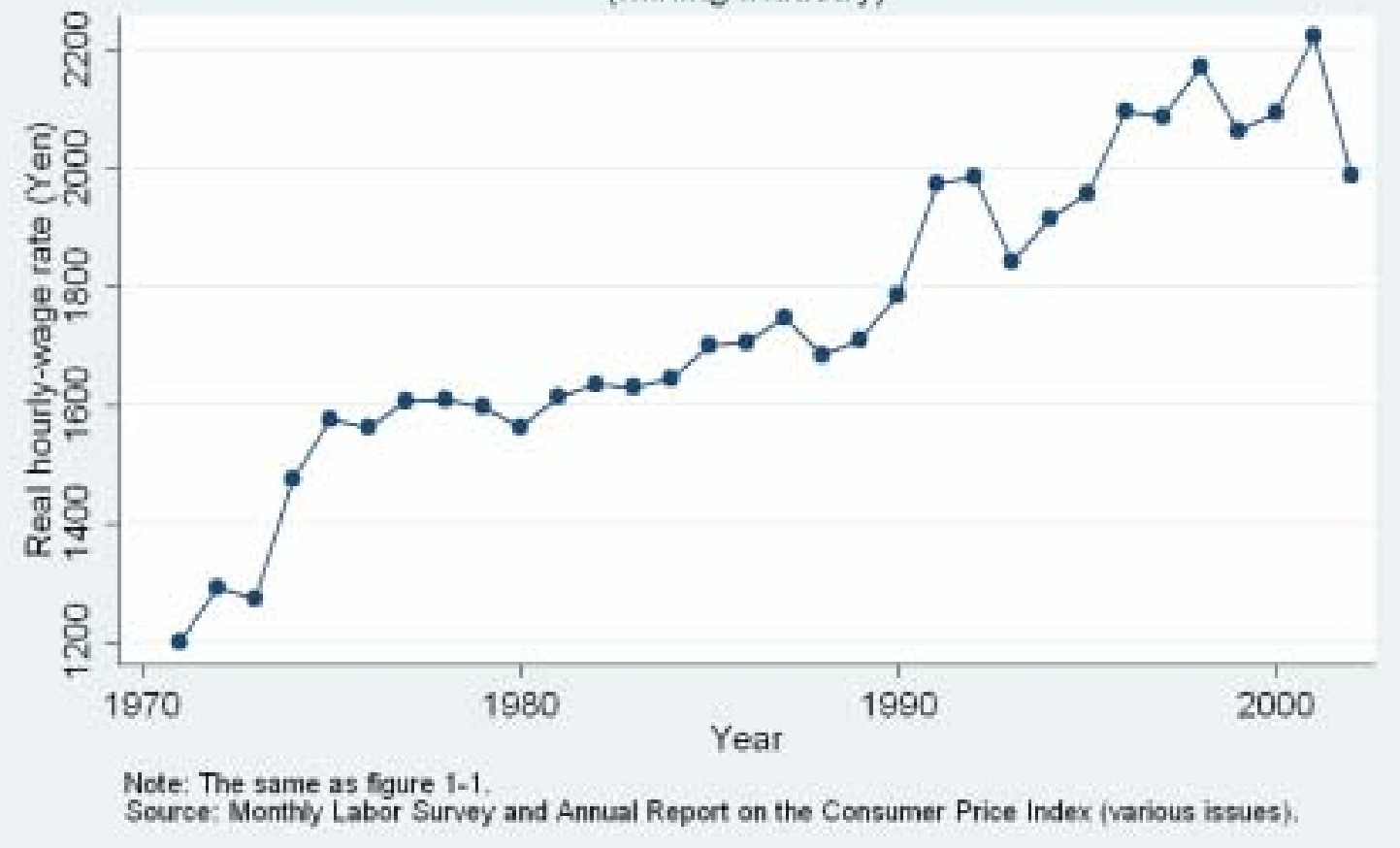

Figure 2-2 Real hourly-wage rate

(Real hourly estate industry)

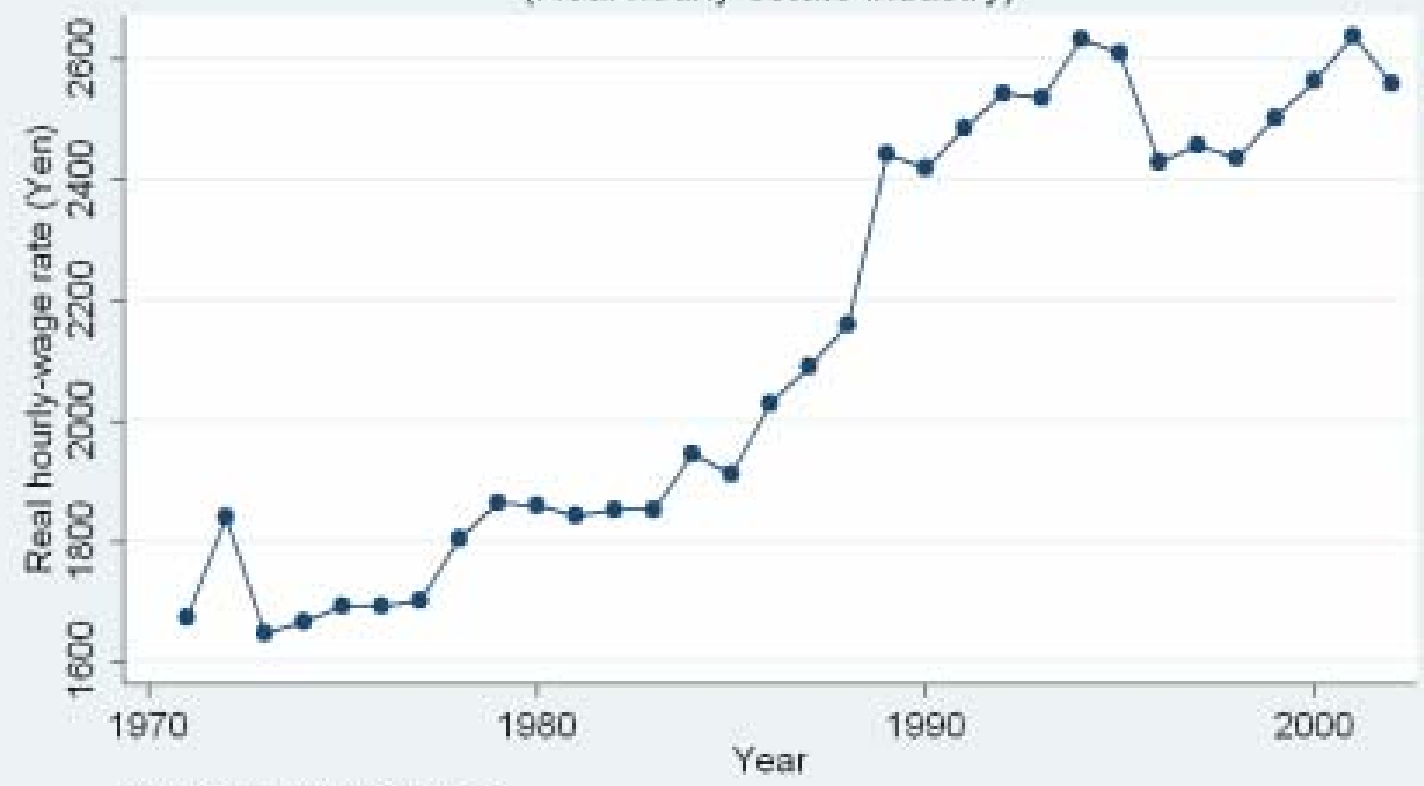

Note: The same as figure $1-1$.

Source: The same as figure 2-1. 


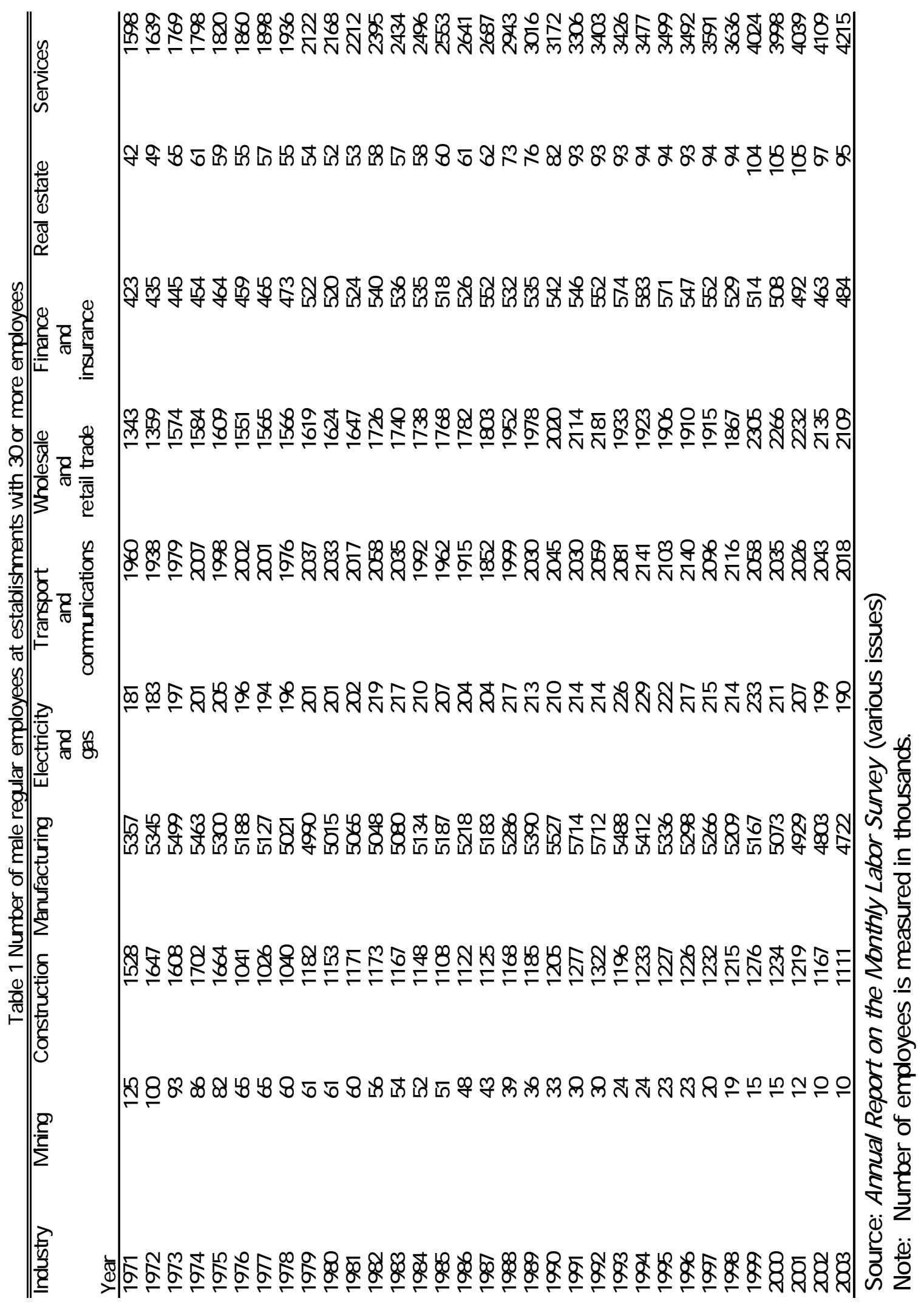




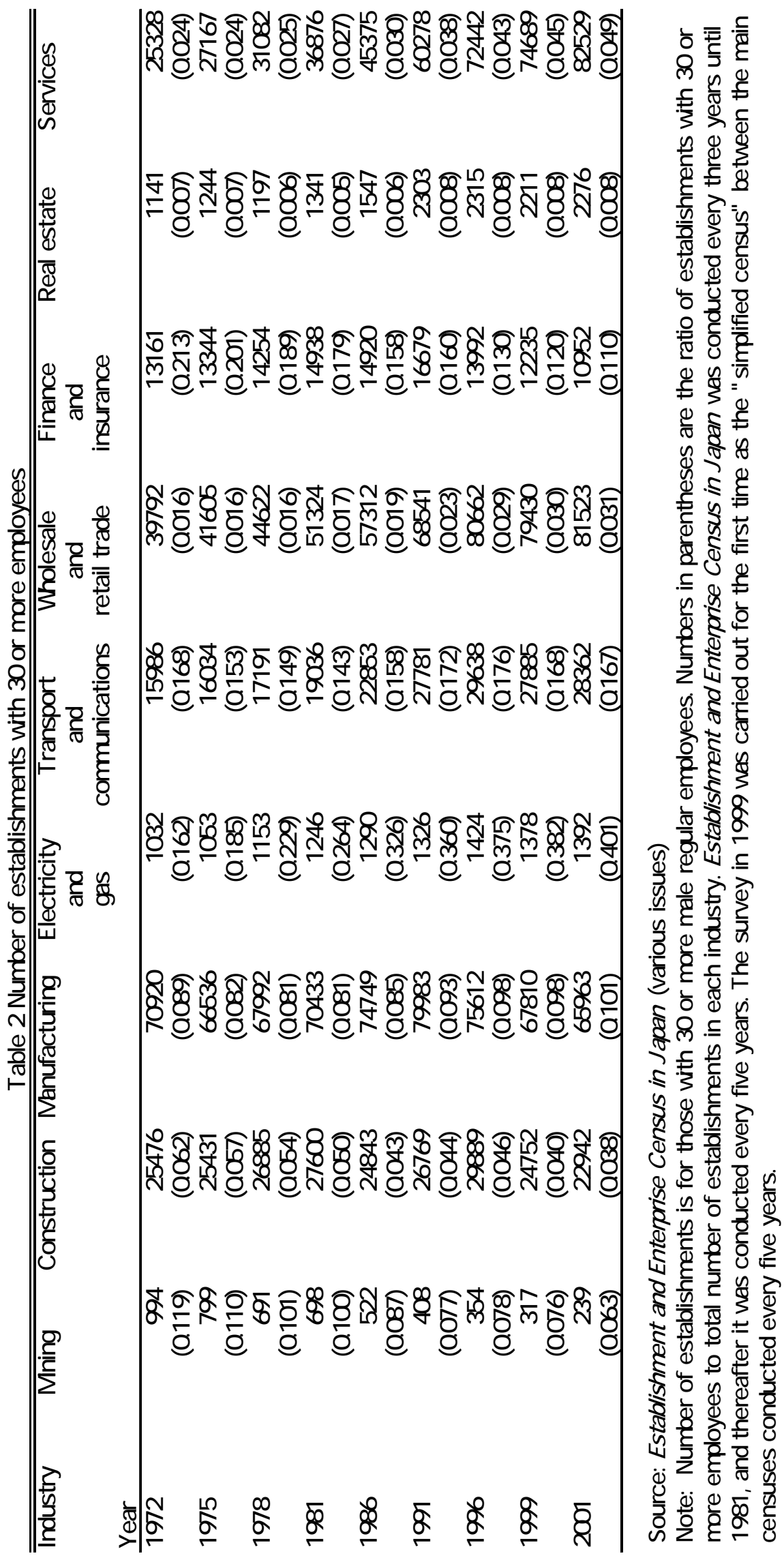




\begin{tabular}{|c|c|c|c|c|c|}
\hline & (A) & (B) & C) & (D) & \\
\hline $\begin{array}{l}\text { Trend variables } \\
\text { Sample exclusion }\end{array}$ & $\begin{array}{l}\text { No } \\
\text { No }\end{array}$ & $\begin{array}{l}\text { Yes } \\
\text { No }\end{array}$ & $\begin{array}{l}\text { No } \\
\text { Yes }\end{array}$ & $\begin{array}{l}\text { Yes } \\
\text { Yes }\end{array}$ & \\
\hline Employer's contribution rate (\%) & $\begin{array}{l}0.036 \text { *** } \\
(0.005)\end{array}$ & $\begin{array}{c}0.022 \\
(0.010)\end{array}$ & $\begin{array}{c}0.007 * \\
(0.004)\end{array}$ & $\begin{array}{c}-0.018 \\
(0.006)\end{array}$ & $* * *$ \\
\hline GDP by industry (In) & $\begin{array}{l}-0.013 \\
(0.018)\end{array}$ & $\begin{array}{l}-0.018 \\
(0.018)\end{array}$ & $\begin{array}{l}0.031 \text { *** } \\
(0.011)\end{array}$ & $\begin{array}{c}0.017 \\
(0.011)\end{array}$ & \\
\hline One- year lag of real wage (In) & $\begin{array}{l}0.561 \\
(0.053)\end{array}$ & $\begin{array}{l}0.534 \\
(0.056)\end{array}$ & $\begin{array}{l}0.817 \\
(0.043)\end{array}$ & $\begin{array}{c}0.731 \\
(0.044)\end{array}$ & $* * *$ \\
\hline One- year lag of labor input (In) & $\begin{array}{l}0.037 \text { *** } \\
(0.012)\end{array}$ & $\begin{array}{l}0.0411^{* * *} \\
(0.013)\end{array}$ & $\begin{array}{c}-0.034 \\
(0.021)\end{array}$ & $\begin{array}{l}-0.035 \\
(0.021)\end{array}$ & $*$ \\
\hline Trend variable & & $\begin{array}{c}0.005 \\
(0.003)\end{array}$ & & $\begin{array}{r}0.010 \\
(0.002)\end{array}$ & $* * *$ \\
\hline Squared trend variable $\times 10^{-2}$ & & $\begin{array}{l}-0.004 \\
(0.004)\end{array}$ & & $\begin{array}{l}-0.007 \\
(0.003)\end{array}$ & $* *$ \\
\hline Constant & $\begin{array}{l}2.531 \text { *** } \\
(0.341)\end{array}$ & $\begin{array}{l}2.817 \text { *** } \\
(0.385)\end{array}$ & $\begin{array}{l}1.415 \text { *** } \\
(0.393)\end{array}$ & $\begin{array}{c}2.377 \\
(0.442)\end{array}$ & $* * *$ \\
\hline Adj. $R^{2}$ & 0.94 & 0.94 & 0.99 & 0.99 & \\
\hline Number of observations & 279 & 279 & 217 & 217 & \\
\hline
\end{tabular}

Note: Standard erros are in parentheses. The asterisks indicate statistical significance at the 1 $\%(* * *), 5 \%(* *)$, and $10 \%(*)$ significance levels. The dependent variable is a logarithm of real hourly- wage rate. The employer's contribution rate is the total rate of health insurance, employees pension, and unemployment insurance. Industry dummies are not reported in this table. Sample period is from 1971 to 2002. 


\begin{tabular}{lccc}
\hline \hline & $\begin{array}{c}(\mathrm{A}) \\
\text { Health } \\
\text { insurance }\end{array}$ & $\begin{array}{c}(\mathrm{B}) \\
\text { Employees } \\
\text { pension }\end{array}$ & $\begin{array}{c}(\mathrm{C}) \\
\text { Unemployment } \\
\text { insurance }\end{array}$ \\
\hline Employer's contribution rate (\%) & $-0.094 * * *$ & -0.005 & $-0.0414^{* *}$ \\
& $(0.019)$ & $(0.005)$ & $(0.016)$ \\
GDP by industry (In) & $0.018 *$ & $0.019 *$ & 0.012 \\
& $(0.010)$ & $(0.011)$ & $(0.011)$ \\
One- year lag of real wage (In) & $0.673 * * *$ & $0.704 * * *$ & $0.703 * * *$ \\
& $(0.041)$ & $(0.045)$ & $(0.042)$ \\
One- year lag of labor input (In) & $-0.046 * *$ & -0.033 & -0.032 \\
& $(0.020)$ & $(0.021)$ & $(0.021)$ \\
Trend variable & $0.013 * * *$ & $0.007 * * *$ & $0.007 * * *$ \\
& $(0.002)$ & $(0.002)$ & $(0.002)$ \\
Squared trend variablex $10^{-2}$ & $-0.017 * * *$ & -0.003 & $-0.007 * *$ \\
& $(0.004)$ & $(0.003)$ & $(0.003)$ \\
Constant & $3.144 * * *$ & $2.406 * * *$ & $2.478 * * *$ \\
& $(0.443)$ & $(0.461)$ & $(0.454)$ \\
Adj. $\mathrm{R}^{2}$ & & & 0.99 \\
& 0.99 & 0.99 & \\
\hline
\end{tabular}

Note: Standard erros are in parentheses. The asterisks indicate statistical significance at the $1 \%(* * *), 5 \%(* *)$, and $10 \%(*)$ significance levels. The dependent variable is a logarithm of real hourly- wage rate. The independent variables include trend and its square, and the observations of the mining and the real estate industries are excluded from the sample. Industry dummies are not reported in this table. Sample period is from 1971 to 2002 (2003 is included only for unemployment insurance). Number of observations is 217 ( 224 for unemployment insurance). 


\begin{tabular}{|c|c|c|c|}
\hline Insurance program & $\begin{array}{l}\text { (A) } \\
\text { Total }\end{array}$ & $\begin{array}{l}(\mathrm{B}) \\
\text { Total }\end{array}$ & $\begin{array}{c}(\mathbf{C}) \\
\text { Employees } \\
\text { pension }\end{array}$ \\
\hline Employer's contribution rate (\%) & $\begin{array}{c}0.006 \\
(0.003)\end{array}$ & $\begin{array}{c}-0.010 \\
(0.012)\end{array}$ & $\begin{array}{c}-0.006 \\
(0.013)\end{array}$ \\
\hline GDP by industry (In) & $\begin{array}{c}0.025 \\
(0.028)\end{array}$ & $\begin{array}{c}0.025 \\
(0.052)\end{array}$ & $\begin{array}{c}0.021 \\
(0.052)\end{array}$ \\
\hline One- year lag of real wage (In) & 0.492 *** & $\begin{array}{l}0.529 \\
(0.099)\end{array}$ & $\begin{array}{l}0.530 \\
(0.099)\end{array}$ \\
\hline One-year lag of labor input (In) & $\begin{array}{c}0.013 \\
(0.033)\end{array}$ & $\begin{array}{c}0.034 \\
(0.048)\end{array}$ & $\begin{array}{c}0.035 \\
(0.048)\end{array}$ \\
\hline Constant & $\begin{array}{l}0.016 \text { *** } \\
(0.004)\end{array}$ & $\begin{array}{c}0.022 \\
(0.011)\end{array} *$ & $\begin{array}{c}0.019 \\
(0.011)\end{array}$ \\
\hline Adj. $R^{2}$ & 0.28 & 0.33 & 0.33 \\
\hline Number of observations & 210 & 56 & 56 \\
\hline
\end{tabular}

Note: Standard erros are in parentheses. The asterisks indicate statistical significance at the $1 \%(* * *)$ and $10 \%(*)$ significance levels. The dependent variable is a logarithm of real hourly- wage rate. The dependent and independent variables are differenced between one- year- before and one- year- after a change in the employer's contribution rate. Sample period is from 1971 to 2002 for column (A). The differenced values between before and after 8 years, which include 1973, 1976, 1980, 1985, 1990, 1991, 1994 and 1996, are used for the estimations of columns (B) and (C). 